\title{
A PERSISTING CHANGE IN PALMAR SWEATING FOLLOWING PREFRONTAL LEUCOTOMY
}

\author{
BY
}

\author{
ALICK ELITHORN, MALCOLM F. PIERCY, and MARGARET A. CROSSKEY \\ From the Neurological Research Unit of the Medical Research Council and the Department of Psychology, \\ National Hospital, Queen Square, London
}

Le Gros Clark (1948) has suggested that the changes in the emotional life brought about by prefrontal leucotomy indicate that the frontal association areas may play an important part in the nervous regulations of autonomic function. As palmar sweating is under sympathetic control and is known to vary in a sensitive fashion with psychological stimuli, it seemed worthwhile to study the effect of leucotomy on resting palmar sweating and on the sudomotor reflexes.

Since the work of Kuno (1934) there has been an unfortunate tendency to regard palmar sweating as independent of thermo-regulatory requirements, and as purely emotional in origin. However, the earlier work of Richter (1929) suggests that palmar sweating is not independent of temperature regulation requirements. Our own preliminary observations confirmed that if the subject is appreciably off heat balance then thermo-regulatory requirements normally take precedence over psychic influences. Our doubts on this score have recently been amply confirmed by Conklin (1951) who showed that when other factors were controlled, palmar skin resistance varied inversely as the environmental temperature.

In order to form an estimate of the influence of thermo-regulatory requirements on palmar skin resistance, records were also kept of the mean environmental temperature, and of palmar skin temperature. Unfortunately, as explained below, skin temperature recordings were not made on all our subjects.

In addition to the influences of thermal and psychological factors, it is likely that palmar sweating is also related to muscular activity (Freeman and Simpson, 1938). This is a factor which in this series of observations it was not practicable to control. Although there is evidence that in this study this factor was not important, its possible influences must be kept in mind in interpreting our findings. Increases in environmental temperature and in muscular activity will tend to increase both palmar sweating and blood flow in the skin and thus, as skin temperature depends on blood flow, these factors will cause a positive correlation between sweat rate and skin temperature. Anxiety, on the other hand (except in so far as it increases metabolism), causes sweating and vasoconstriction. This variable will therefore cause a negative correlation between palmar sweating and skin temperature. Thus the correlation coefficient derived from concurrent observations on sweat rate and blood flow will vary between -1 and +1 depending on the respective contributions of these factors. That is to say, this value will increase positively as psychic factors are reduced in importance as a variable.

\section{Methods}

The palmar skin resistance was measured with an apparatus similar to that described by Grant (1946). Recordings of the psychogalvanic responses were made on photographic paper. The technique has been described and illustrated elsewhere (Elithorn, Piercy, and Crosskey, 1951). Palmar skin temperature was measured originally with a commercial "thermistor" ; this was inadvertently broken by a patient and because of its long period of adaptation it was, after a delay, replaced by thermocouples and a galvanometer.

In the absence of a constant temperature room recordings were made at the temperature prevailing in the laboratory, which was also recorded. The subject rested in a sitting position with the arms supported comfortably at heart level. In addition to the records of laboratory temperature, we obtained figures for London temperatures as recorded at midday on the Air Ministry roof. Correlation coefficients were calculated for the initial skin resistance and London temperature and also for the final skin resistance and the laboratory temperature. Our subjects were present in the 
laboratory for about half an hour. This time was not sufficient for them to establish a new thermoregulatory balance and the correlations presented are those for the initial readings and the London temperature.

In interpreting these correlation coefficients it must be remembered that during the immediately pre- and post-operative periods the patients were to some extent protected from the environmental temperature by the hospital. During the follow-up period they attended as out-patients. For some subjects, in addition to the observations on resting skin resistance, the psycho-galvanic responses to a sudden loud noise and to a maximal deep breath were also recorded. In others the responses to painful stimuli and the threat of painful stimuli were recorded. (The effect of leucotomy on these latter responses will be reported elsewhere.)

The number of patients available was small and the opportunities to study each one variable. Further, it was expected that they would show individual variations to a surgical procedure whose extent was always slightly doubtful. It was decided, therefore, to make as many serial observations on each patient as circumstances permitted. Relevant clinical details are mentioned in association with the individual findings. Full clinical details will be published elsewhere.

\section{Results}

Table I shows the means and the standard deviations calculated from the 298 occasions on which skin temperature and skin resistance were

TABLE I

SKIN RESISTANCE, SKIN TEMPERATURE, AND LONDON TEMPERATURE

\begin{tabular}{|c|c|c|c|}
\hline Period of Observation & $\begin{array}{l}\text { Pre- } \\
\text { operatively }\end{array}$ & $\begin{array}{l}\text { First Three } \\
\text { Months Post- } \\
\text { operatively }\end{array}$ & $\begin{array}{l}\text { After } \\
\text { Third } \\
\text { Month }\end{array}$ \\
\hline Number of observations & 94 & 140 & 64 \\
\hline $\begin{array}{l}\text { Mean skin resistance in } \\
\text { ohms } \times 10^{3}\end{array}$ & $(\mathrm{~S} . \mathrm{D} .=45 \cdot 9)$ & $\begin{array}{c}169 \\
(\text { S.D. }=38 \cdot 2)\end{array}$ & $\begin{array}{c}156 \\
\text { (S.D. }=56 \cdot 2)\end{array}$ \\
\hline $\begin{array}{l}\text { Mean skin temperature } \\
\text { in }{ }^{\circ} \mathrm{F} \text {. }\end{array}$ & $\begin{array}{c}81 \cdot 7 \\
\text { (S.D. }=7 \cdot 3)\end{array}$ & $\begin{array}{c}85 \cdot 5 \\
(\mathrm{~S} . \mathrm{D} .=5 \cdot 5)\end{array}$ & $\begin{array}{c}87 \cdot 4 \\
\text { (S.D. }=7 \cdot 2)\end{array}$ \\
\hline $\begin{array}{l}\text { Mean London tempera- } \\
\text { ture in }{ }^{\circ} \mathrm{F} \text {. }\end{array}$ & $\begin{array}{c}53 \cdot 8 \\
(\text { S.D. }=10 \cdot 2)\end{array}$ & $\begin{array}{c}55 \cdot 3 \\
(\text { S.D. }=20 \cdot 0)\end{array}$ & $\begin{array}{c}59 \cdot 5 \\
\text { (S.D. }=11 \cdot 8)\end{array}$ \\
\hline
\end{tabular}

Mean values obtained with 23 subjects.

both recorded. These have been grouped into (1) pre-operative observations, (2) post-operative observations made in the first three post-operative months, and (3) follow-up observations made during the subsequent 21 months. A varying number of observations was made on 23 patients, and in order to avoid undue weighting by those patients on whom most observations were made, the overall means for each period have been calculated from the mean value for each patient for each period.

It will be seen that for the period immediately following the operation there is a rise in the mean values for skin resistance (indicating a decrease in sweating), in skin temperature, and in the London temperature. In the follow-up period the mean value for skin resistance has fallen towards the preoperative value, but the values for mean skin temperature and mean London temperature have risen further. Although the variability of these means as expressed by their standard deviations is high, Fisher's $t$ test for the difference between means of paired observations shows that the changes in skin resistance and in skin temperature which follow the operation are both significant at the $5 \%$ level of confidence $(t=2.34$ and 2.11 respectively, $n=22$ ). The increase in London temperature does not satisfy this test of statistical significance $(t=$ $1.49: 0 \cdot 1<\mathrm{P}<0.2$ ). However, by the follow-up period the mean environmental temperature has risen to $59.5^{\circ} \mathrm{F}$., an increase of $5.7^{\circ} \mathrm{F}$. over the mean temperature of the pre-operative period. This change in temperature satisfies the $t$ test of significance $(t=2.46: 0.02<P<0.05)$. Although our observations were spread over two years it is clear that we must take into account a mean rise in environmental temperature which accompanies our post-operative observations. This is probably related to the known tendency for psychiatric patients to be at their worst in the late winter, and to the tendency of our medical and surgical colleagues to take their holidays in the summer months. As a consequence, the majority of our patients were operated on in the winter.

Tests of significance for the skin resistance and the skin temperature show that during the follow-up period the skin resistance is no longer significantly different from the pre-operative control findings $(t=0.90: 0.3<P<0.4)$. The change in skin temperature has, however, increased and has a higher level of confidence $(\mathrm{t}=3 \cdot 16: 0.01<\mathrm{P}<0.02)$. Table II shows the correlations which have been derived from these observations. In all three periods the correlations of both palmar sweating and palmar temperature with the London temperature are positive. The correlation coefficient for palmar sweating and London temperature reaches a value which satisfies tests of significance only during the third or follow-up period. During the first two periods the patients were to some extent protected from environmental changes by their presence in 
TABLE II

CORRELATION COEFFICIENTS BETWEEN SWEAT RATE (SKIN RESISTANCE), BLOOD FLOW (SKIN TEMPERATURE) AND LONDON TEMPERATURE FOR THE SAME PERIODS AS TABLE I

\begin{tabular}{|c|c|c|c|}
\hline $\begin{array}{l}\text { Period of } \\
\text { Observation }\end{array}$ & $\begin{array}{c}\text { Pre- } \\
\text { operative }\end{array}$ & $\begin{array}{l}\text { First Three } \\
\text { Months } \\
\text { Post } \\
\text { operatively }\end{array}$ & $\begin{array}{l}\text { After Third } \\
\text { Post- } \\
\text { operative } \\
\text { Month }\end{array}$ \\
\hline Number of observations & 94 & 140 & 64 \\
\hline $\begin{array}{c}\text { Sweat rate and London } \\
\text { temperature } \ldots\end{array}$ & $+0 \cdot 140$ & +0.174 & $+0 \cdot 321^{*}$ \\
\hline $\begin{array}{c}\text { Blood flow and London } \\
\text { temperature } \ldots\end{array}$ & $+0 \cdot 291^{*}$ & $+0 \cdot 360^{* * *}$ & $+0.485^{* * *}$ \\
\hline $\begin{array}{cccc}\text { Sweat rate } & \text { and blood } \\
\text { flow } & \ldots & \ldots & \ldots\end{array}$ & +0.142 & $+0 \cdot 327^{* * *}$ & $+0 \cdot 276^{*}$ \\
\hline
\end{tabular}

$*$ Significant at $5 \%$ level of confidence.
$* * *, \quad, 0.1 \%, ", \quad$,

hospital. In spite of this the correlation of skin temperature with the external London temperature is significant in each period, and it is likely that heat elimination requirements play a dominant role in determining palmar skin temperature. It seems reasonable, therefore, to suggest that in the present series the skin temperature may be a more reliable indicator than London temperature of heat elimination requirements. Accepting this viewpoint for the moment, we may say that the post-operative increase in the correlation between the skin resistance and the skin temperature suggests that, after leucotomy, sweating is more closely related to thermo-regulatory requirements than to psychic factors. This dependence of sweating on thermoregulatory requirements would appear to be most marked in the immediate post-operative period. Since the correlation coefficients show that in all periods skin temperature correlates positively with the environmental temperature, it is reasonable to conclude that the post-operative rise in mean skin temperatures shown in Table I may well depend very largely on the concomitant increases in environmental temperature. This change in temperature cannot account for the marked decrease in sweating (raised skin resistance) which occurs in the post-operative period. In fact, if psychological factors are held constant an increase in sweating must be expected in association with an increased environmental temperature. The further increase in temperature in the follow-up period could have contributed to the subsequent fall in the resistance towards the pre-operative value.

Adaptation Effects and Controls.-Unfortunately it was not possible to make similar serial observations on patients undergoing other intracranial operations. One patient undergoing a two-stage lumbar sympathectomy for hypertension was studied in detail. Following both operations she failed to show any marked rise in skin resistance and in fact showed a fall after each operation which may have been due to compensating sympathetic overactivity in the upper limbs. However, not all our patients had a full leucotomy, and it has proved possible to show clearly that the disturbance in palmar sweating is related to the extent of surgical intervention.

It has recently been confirmed by Conklin (1951) that skin resistance measurements show slight but definite adaptation when the observations are repeated on subsequent days. In order to exclude this as a possible cause of our findings we have analysed four seriatim observations, two immediately before and two immediately after the operation. The results are presented in Table III. They have been summarized separately for two groups of patients : first, 15 subjects who had a full standard leucotomy and, secondly, seven subjects who had minor surgical procedures-either unilateral leucotomies or bilateral operations of limited extent. One subject, who had only one preoperative recording, has been omitted. In Table III those means, which are significantly different from

TABLE III

SERIATIM OBSERVATIONS ON RESTING SKIN RESISTANCE FOR 22 SUBJECTS

\begin{tabular}{|c|c|c|c|c|c|c|c|c|c|c|}
\hline & \multicolumn{5}{|c|}{$\begin{array}{c}\text { Standard Leucotomy } \\
(\mathbf{N}=15)\end{array}$} & \multicolumn{5}{|c|}{$\begin{array}{c}\text { Sub-standard Leucotomy } \\
(\mathbf{N}=7)\end{array}$} \\
\hline & Session A & Session B & & Session C & Session D & Session A & Session B & & Session C & Session D \\
\hline & $\begin{array}{c}\text { Av. } 6 \text { days } \\
\text { Pre- } \\
\text { operatively }\end{array}$ & $\begin{array}{l}\text { Av. } 4 \text { days } \\
\text { Pre- } \\
\text { operatively }\end{array}$ & \multirow{3}{*}{ 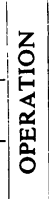 } & $\begin{array}{l}\text { Av. } 7 \text { days } \\
\text { Post- } \\
\text { operatively }\end{array}$ & $\begin{array}{l}\text { Av. } 11 \text { days } \\
\text { Post- } \\
\text { operatively }\end{array}$ & $\begin{array}{l}\text { Av. } 6 \text { days } \\
\text { Pre- } \\
\text { operatively }\end{array}$ & $\begin{array}{l}\text { Av. } 4 \text { days } \\
\text { Pre- } \\
\text { operatively }\end{array}$ & \multirow{3}{*}{ 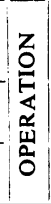 } & $\begin{array}{c}\text { Av. } 7 \text { days } \\
\text { Post- } \\
\text { operatively }\end{array}$ & $\begin{array}{l}\text { Av. } 11 \text { days } \\
\text { Post- } \\
\text { operatively }\end{array}$ \\
\hline $\begin{array}{l}\text { Mean skin resis- } \\
\text { tance in ohms } \times 10^{3}\end{array}$ & $\begin{array}{c}154 \\
\text { (S.D. }=67 \cdot 0)\end{array}$ & $\begin{array}{c}142 \\
\text { (S.D. }=47.9)\end{array}$ & & $\begin{array}{c}213^{* * *} \\
(\mathrm{~S} . \mathrm{D} .=68 \cdot 0)\end{array}$ & $\begin{array}{c}202 \\
\text { (S.D. }=77 \cdot 6)\end{array}$ & $\begin{array}{c}175 \\
(\text { S.D. }=70 \cdot 1)\end{array}$ & (S.D. $=41.9)$ & & $\begin{array}{l}157 \\
\text { (S.D. }=50 \cdot 8)\end{array}$ & (S.D. $=45 \cdot 9)$ \\
\hline $\begin{array}{l}\text { Mean London } \\
\text { temperature in }{ }^{\circ} \mathrm{F} \text {. }\end{array}$ & $\begin{array}{c}55 \cdot 2 \\
(\mathrm{~S} . \mathrm{D} .=6 \cdot 5)\end{array}$ & $\begin{array}{c}55 \cdot 0 \\
(\mathrm{~S} . \mathrm{D} .=9 \cdot 5)\end{array}$ & & $\begin{array}{c}53 \cdot 3 \\
\text { (S.D. }=11 \cdot 2)\end{array}$ & $\begin{array}{c}55 \cdot 9 \\
(\text { S.D. }=9 \cdot 5)\end{array}$ & $\begin{array}{c}51 \cdot 9 \\
(\mathrm{~S} . \mathrm{D} .=6 \cdot 3)\end{array}$ & $\begin{array}{c}54 \cdot 2 \\
(\text { S.D. }=8 \cdot 9)\end{array}$ & & $\begin{array}{c}50 \cdot 4 \\
(S . D .=9 \cdot 4)\end{array}$ & $\begin{array}{c}56 \cdot 0 \\
(\text { S.D. }=12 \cdot 7)\end{array}$ \\
\hline
\end{tabular}

The asterisks show those figures which are significantly different from the preceding session at or above the $5 \%$ level of confidence. $* * *$ denotes significant at $0 \cdot 1 \%$ level of confidence. 
the values found in the immediately preceding session, are indicated.

The only significant change between seriatim sessions occurs in the group undergoing full leucotomy. For this group Fisher's $t$ test shows that the differences between the means for the two preoperative sessions are not significant. The mean skin resistances for the two post-operative sessions are both significantly higher (at the $1.0 \%$ level of confidence) than those in either pre-operative session. Further, the difference between the means of the two postoperative sessions is not significant. In the group of seven patients who had restricted operations, none of the changes between sessions is significant. Of these seven patients, only four showed a rise in skin resistance between sessions $B$ and $C$, i.e., between the immediately pre-operative and the immediately post-operative session. Of the 15 patients receiving a full leucotomy only one failed to show such a rise.

Although the number of subjects is small, it is possible to show by means of a contingency table that environmental temperatures play a role in determining individual changes from session to session. Such a presentation has the advantage of demonstrating more directly the irrelevance of environmental temperature variations to the marked decrease in palmar sweating brought about by leucotomy. Table IV shows (1) the contingency of

TABLE IV

RELATIONSHIP BETWEEN CHANGES IN SKIN RESISTANCE AND CHANGES IN LONDON TEMPERATURE FOR 22 SUBJECTS

\begin{tabular}{l|l|l}
\hline & $\begin{array}{c}\text { Rise in Skin } \\
\text { Resistance }\end{array}$ & $\begin{array}{c}\text { Fall in Skin } \\
\text { Resistance }\end{array}$ \\
\hline 1. Changes between Session A and Session B. &
\end{tabular}

\begin{tabular}{llll}
\hline Rise in London temperature & $\ldots$ & 3 & 7 \\
\hline Fall in London temperature & $\ldots$ & 7 & 5 \\
\hline
\end{tabular}

2. Changes between Session B and Session C.

\begin{tabular}{ll|l|l}
\hline Rise in London temperature &. & 9 & 1 \\
\hline Fall in London temperature &. & 9 & 3 \\
\hline
\end{tabular}

changes in skin resistance between sessions $\mathrm{A}$ and $B$ on changes in London temperature and (2) the contingency of changes in skin resistance between sessions $B$ and $C$ on changes in London temperature. It can be seen that in the case of the two preoperative sessions this contingency is marked but in the case of the two sessions separated by the operation the rise in skin resistance is independent of changes in London temperature. Any surgical operation is sometimes followed by a period of impaired temperature regulation with pyrexia. The ward records of axillary temperature showed such a disturbance for most of our subjects but this lasted only a few days. Observations on the oral temperatures of 12 of our subjects confirmed that our results could not be explained as a failure of temperature regulation, the mean value for 52 observations of a three-minute oral temperature pre-operatively being $98 \cdot 2^{\circ} \mathrm{F}$. (S.D. $=0 \cdot 66$ ). For 64 observations made in the first three months postoperatively the mean value was $98.3^{\circ} \mathrm{F}$. (S.D. = $0 \cdot 68$ ). These means are not significantly different.

Follow-up Studies.-The overall means presented in Table I suggested that the effect of leucotomy on the skin resistance persisted for at least three months, though this observation did not reach a significant level of confidence. The mean value for the skin resistance during the follow-up period included however the observations made on subjects who had had only partial leucotomies. Further, most of the recordings were made on days with a relatively high environmental temperature. In order to throw further light on this point we have undertaken a separate analysis of our follow-up observations on those subjects who had a full leucotomy and were examined at least six months after operation. Twelve subjects came into this category and for these 12 subjects we have analysed the observations made at their most recent visit, thus ensuring the maximum possible lapse of time between the operation and follow-up observation. The mean follow-up period is two years, the actual values in months for the 12 subjects being $6,11,11,13,18$, $18,2 \tau, 32,35,38,39$, and 43 . Of these 12 subjects, the seven whose follow-up time is presented in italics showed skin resistance levels higher than both the values recorded in session A or session B. The mean values for this group are given in Table $\mathrm{V}$, where this follow-up session is designated $F$. The mean skin resistance value for this session is higher than those recorded pre-operatively. The difference between session $F$ and session $B$ is significant at the $1 \%$ confidence level, but the difference between session $\mathrm{F}$ and session $\mathrm{A}$ does not reach a significant $(5 \%)$ level of confidence. This difference cannot be accounted for by environmental changes, the mean temperature being slightly higher for the follow-up observations than for either of the pre-operative sessions.

Thus we can conclude that in this group of cases, a standard prefrontal leucotomy caused a marked decrease in palmar sweating which persisted well beyond the immediate post-operative period, and further that this is not due to a failure of the temperature-regulating mechanism. Control observations 
TABLE V

FOLLOW-UP STUDIES OF 12 LEUCOTOMY PATIENTS

\begin{tabular}{|c|c|c|c|c|c|c|c|c|}
\hline & & & Session A & Session B & & Session C & Session D & $\begin{array}{l}\text { Follow-up } \\
\text { Session F }\end{array}$ \\
\hline Mean levels of skin resistance in ol & $\times 10^{3} \ldots$ & $\cdots$ & $($ S.D. $=74.8)$ & (S.D. $=65 \cdot 1)$ & \multirow{3}{*}{$\begin{array}{l}z \\
0 \\
\underline{G} \\
\overleftarrow{s} \\
\underline{u} \\
\text { w } \\
0\end{array}$} & $\begin{array}{c}203 \\
(S . D .=63 \cdot 8)\end{array}$ & $($ S.D. $=64 \cdot 4)$ & $\begin{array}{c}180 \\
(\text { S.D. }=65 \cdot 5)\end{array}$ \\
\hline Mean London temperature in ${ }^{\circ} \mathrm{F}$. & $\cdots$ & $\cdots$ & $\begin{array}{c}55 \cdot 1 \\
(\mathrm{~S} . \mathrm{D} .=7 \cdot 0)\end{array}$ & $\begin{array}{c}55 \cdot 0 \\
(S . D .=10 \cdot 6)\end{array}$ & & $\begin{array}{c}54 \cdot 7 \\
(S . D .=11 \cdot 6)\end{array}$ & $\begin{array}{c}57 \cdot 0 \\
(\mathrm{~S} . \mathrm{D} .=9 \cdot 7)\end{array}$ & $\begin{array}{c}55 \cdot 9 \\
(\mathrm{~S} . \mathrm{D} .=13 \cdot 1)\end{array}$ \\
\hline Mean days to operation $\ldots$ & . & . & -6 & -4 & & +8 & +10 & +764 \\
\hline
\end{tabular}

The asterisks show those figures which are significantly different from those found at follow-up session F. ** Significant at $1 \%$ level of confidence.

show that it is related to the extent of tissue damaged and is not caused by the anaesthetic or surgical operation per se. The material is not adequate to indicate whether the site of the lesion is important.

Individual Results.-We have argued elsewhere (Elithorn and others, 1954) that the effect on autonomic functions of surgical trauma to the frontal lobes will vary in individual subjects and will in the case of psychiatric patients depend to a large extent on the nature of the pre-operative morbid state. Most workers interested in skin resistance agree with Richter $(1928,1929)$ that the palmar resistance tends to be high in depressive illnesses and is low in conditions associated with anxiety. Unfortunately almost all our subjects were both depressed and anxious; not one was severely retarded. It is interesting to note, however, that the patient who showed the highest pre-operative skin resistance was subject J.G. who was the only patient suffering from a recurrent endogenous depression.

Fig. 1 shows graphically the types of change which were observed in individual patients.

Patient F. C. (Hospital No. 11564).-This patient, a woman aged 41 (Fig. 1, 1), shows the effect of the standard operation on the skin resistance of a patient of life-long anxious and hypochondriacal personality, who at the age of 38 developed an agitated depressive illness. Leucotomy produced a complete remission. Personality changes were mild and beneficial in that she was no longer abnormally over-anxious, but showed no unequivocal changes for the worse. With this patient the change in skin resistance was not marked. The post-operative values are well within normal limits but equally are consistently higher than those recorded pre-operatively.

Patient N. P. (Hospital No. 11405).-This patient, a woman aged 43 , suffered from a chronic anxiety state with a morbid preoccupation with her total alopecia, and a constant fear that her wig would be detected, Following standard leucotomy there was a definite reduction in her tension, though the recurrence of her fears led eventually to a second operation. Following a prolonged period of rehabilitation she made a good recovery. Fig. 1, 2 shows that after her first operation there was a marked increase in skin resistance.

Patient E. C. (Hospital No. 12233).-Fig. 1, 3 shows the effect of a standard leucotomy on a patient who suffered from a chronic paranoid schizophrenic illness of at least 10 years' duration. The operation produced no alteration in the essential illness but a definite temporary reduction in tension. After leucotomy there was a marked temporary elevation of the skin resistance.

Patient J. G. (Hospital No. 13310).-This lady, aged 66 years, was suffering from her second attack of endogenous depression, an illness of three years' duration, in her instance attended by considerable fear, anxiety, and somatic sensations. There was no pathological guilt or delusions or hallucinations. Retardation was not marked. A standard leucotomy produced a complete remission of her illness and a definite frontal lobe syndrome. The resting skin resistance readings (Fig. 1, 4) obtained from this patient were quite low at first, but rose quickly to an abnormally high level as she became accustomed to the test procedure; her contact with the environment and her marked tendency to react with anxiety are well demonstrated by the low level recorded at the first session and the sudden drop in resistance which accompanied her transfer to the surgical ward. After leucotomy she showed the usual post-operative high levels of palmar skin resistance although in fact these are less high than those associated with her depressive illness

Patient E. M. (Hospital No. 8663).-This patient, a woman aged 53, suffered from an involution hypochondriasis which centred around abnormal throbbing sensations within her belly. Rostral leucotomy produced a very slight and transient improvement. A standard leucotomy a year later again failed to alter her main symptoms but there was undoubtedly a great reduction in the anxiety and depression associated with her illness. Fig. 1, 5 shows that following the minor rostral operation there was no marked effect on the palmar sweating. Following the standard operation the skin resistance showed a very definite rise similar to that found with most patients who had had standard leucotomies.

Psychogalvanic Responses.-The psychogalvanic responses which were recorded to a sudden loud noise and to maximal inspiration showed great variability both as between different subjects and as 


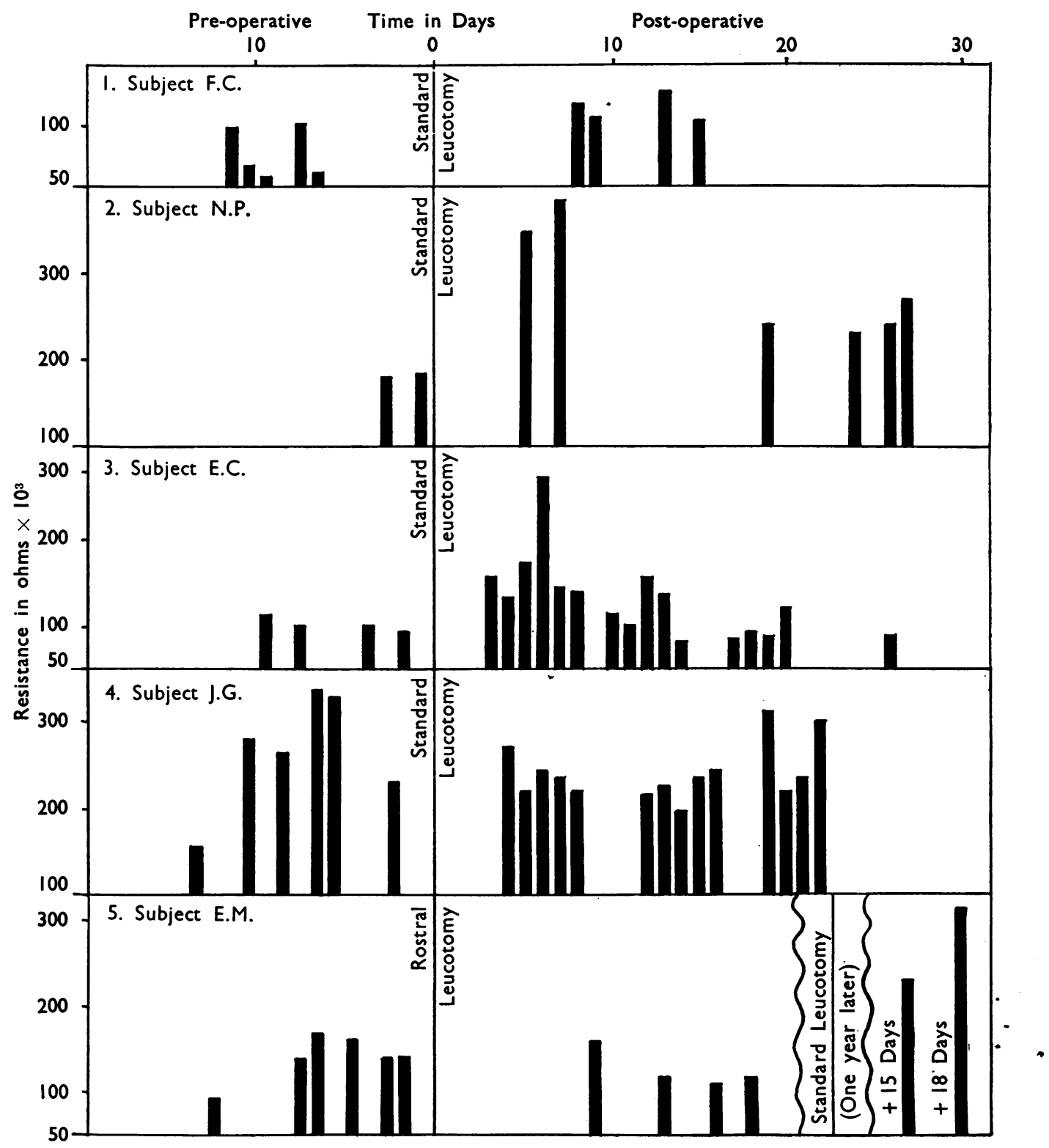

Fig. 1.-Changes in resting skin resistance following prefrontal leucotomy. 
between different occasions for the same subject. There was definite adaptation of the responses with repetition of the stimulus-especially the startle noise. For the group as a whole the gradual decrease in size of responses from session to session was temporarily interrupted by leucotomy. The effect did not satisfy tests of significance and inspection of the individual results suggested that individual subjects responded in opposite ways to leucotomy. In those in whom anxiety was the prominent preoperative symptom leucotomy tended to produce a marked reduction in the responses. Where depression was predominant the responses were for a short time post-operatively much exaggerated in size, but quickly adapted with repetitions. Although these results are not presented in detail and were not suitable for statistical analysis they are mentioned here because they confirm Ashby and Bassett's tentative conclusions. The results obtained with other stimuli will be reported in detail elsewhere.

\section{Discussion}

A paper by Ashby and Bassett (1950) is, as far as the present authors are aware, the only report of an investigation primarily undertaken to study the effect of leucotomy on palmar sweating. Several other authors have used various estimations of palmar sweat function amongst other " indices" of "autonomic reactivity". Thus, Malmo and Shagass (1950) state that following lobotomy patients show larger psychogalvanic responses to painful stimuli. The Columbia-Greystone Associates $(1949,1952)$ report that various forms of psychosurgery cause an increase in the fall in palmar skin resistance which follows the intravenous injection of " methacholine". Unfortunately these authors do not give the initial levels of skin resistance though they mention in passing that these were very high post-operatively in the two patients who underwent cortical thermocoagulation. Glaser (1952) in an interesting study has considered carefully the effect of the preoperative mental state of his subjects. He compares the effects of two types of frontal topectomy (dorsal and orbital) on the autonomic stability of two groups of schizophrenics. Both paranoid schizophrenics and hebephrenic-catatonic schizophrenics showed an increase in resting skin resistance and a greater reactivity to intravenous "mecholyl", regardless of which type of operation was performed. With the cold pressor test, the paranoid group showed a reduction in reactivity, while the hebephreniccatatonic group, which before operation had been hyporeactive, showed increased reactivity.

Ashby and Bassett (1950) examined only the reflex activity of the skin resistance. They compared the psychogalvanic responses to eight startle stimuli in two matched groups, each of 21 patients with varied symptoms. The group which had previously been subjected to leucotomy was significantly less reactive than the control patients. In a smaller but more precise study reported at the same time, they examined six subjects on three occasions before and on three occasions after the operation. Some of these subjects showed increased responses following leucotomy and some decreased responses. This effect they found to be significant at the $1 \%$ level of confidence. Ashby and Bassett examined patients subjected to both standard leucotomy and orbital " ice pick" leucotomy. They do not report any difference in results between subjects undergoing these two types of operation, nor do they say in what particular the effect of the operation depended on the pre-operative clinical picture.

Mettler and Landis (1952) writing the concluding chapter to the second of the Columbia-Greystone studies say :

"The present data tend to confirm the general findings of the previous project in which it was pointed out that the physiological effects of granular frontal
cortical removal were qualitatively and quantitatively less extensive than the literature would lead one to suppose."

Unfortunately the Columbia-Greystone project, which is clearly the most detailed and comprehensive 8 physiological investigation to date on the effects of various psychosurgical procedures, was undertaken on deteriorated schizophrenics. Our own analysis of the literature which is given above and which is here confined to those papers dealing with the effect of leucotomy on palmar skin resistance, combined with our own observations, supports the following conclusions.

Palmar sweating in mental disease may be increased in association with subjective feelings of anxiety, agitation or distress. In so far as these symptoms are relieved by leucotomy, there is likely to be a concomitant decrease in palmar sweating. In depressive illnesses-especially those of the endogenous type associated with retardation and poverty of thought-there is said to be (Richter 1928) a relative failure of palmar sweating and a decrease in the psychogalvanic responses to many types of stimuli. (Our present experience is limited to one case.) Following a successful leucotomy (as in fact happens in our one case) palmar sweating is likely to increase and responsiveness to return. In the present series, with one exception (a hypertensive patient who showed clinical evidence of a posterior and severe leucotomy and for a few days postoperatively suffered from syncopal attacks) we have 
not found any evidence of failure of homeostatic physiological mechanisms. Indeed, the positive correlation between sweat rate and skin temperature was higher in the immediate post-operative period than either before operation or during the follow-up period. Carscallen, Buck, and Hobbs (1951) have shown that after leucotomy schizophrenics show improved temperature regulation. These findings also are in line with Reitman's (1945) conclusions that with schizophrenic patients after standard leucotomy there is a tendency towards increased rather than decreased "homeostasis". We would add that leucotomy also reduces the abnormal autonomic activity associated with the mental disease.

\section{Summary}

Studies on palmar skin resistance (palmar sweating) have been carried out on 16 patients undergoing bilateral standard leucotomy, four undergoing unilateral leucotomy, and three undergoing rostral cortical undercutting.

A group of 12 patients subjected to standard leucotomy showed post-operatively a significant increase in skin resistance which was present, though to a diminished extent, more than six months after leucotomy (mean follow-up time two years). This effect was not detected in the group of seven patients undergoing minor psychosurgical procedures.

Individual studies showed that the alterations in skin resistance which followed prefrontal leucotomy were related to the changes which occurred in the mental state. They were not related to changes in thermo-regulation.

The literature on the effects of prefrontal leucotomy on palmar skin resistance is reviewed.

Our thanks are due to the physicians and surgeons of the National Hospital who allowed us to study patients under their care, to Dr. Eliot Slater, under whose care most of these patients were, and who saw the remainder in consultation, we are particularly indebted for an authoritative opinion on their psychiatric state. To Dr. Carmichael and Professor Zangwill we are grateful for advice, criticism, and material help.

\section{REFERENCES}

Ashby, W. R., and Bassett, M. (1950). J. ment. Sci., 96, 458.

Carscallen, H. B., Buck, C. W., and Hobbs, G. E. (1951). Arch. Neurol. Psychiat., Chicago, 65, 206.

Clark, W. E. Le Gros (1948). Lancet, 1, 353.

Conklin, J. E. (1951). Amer. J. Physiol., 64, 78.

Columbia-Greystone Associates (1949). Selective Partial Ablation of the Frontal Cortex, ed. Mettler, F. A. Hoeber, New York 1952). Psychosurgical Problems, ed. Mettler, F. A. Routledge and Kegan Paul, London.

Elithorn, A., Piercy, M. F., and Crosskey, M.A. (1951). Journal of Neurology, Neurosurgery and Psychiatry, 14, 209.

Free,

G. Lend Simpson, R. M. (1938). J. gen. Psychol., 18, 319.

Glaser, G. H. (1952). J. nerv. ment. Dis., 115, 189.

Grant, D. A. (1946). Amer. J. Psychol., 59, 149.

Kuno, Y. (1934). The Physiology of Human Perspiration. Churchill, London.

Malmo, R. B., and Shagass, C. (1950). Arch. Neurol. Psychiat., Chicago, 63, 113 .

Mettler, F. A., and Landis, C. (1952). In Psychosurgical Problems, p. 313. London.

Reitman, F. (1945). J. ment. Sci., 91, 318.

Richter, C. P. (1928). Arch. Neurol. Psychiat., Chicago, 19, 488. 